\title{
Effects of Dextran Sulfate on Stabilization of Milk Lipoprotein Lipase and VLDL Triglyceride Hydrolysis in Vitro
}

\author{
Nobuo Matsuoka, Yasushi Saito* and Sho Yoshida* \\ Clinical Laboratory, Kawatetsu Chiba Hospital, Chiba 280, \\ and *the Second Department of Internal Medicine, School \\ of Medicine, Chiba University, Chiba 280
}

\begin{abstract}
Matsuoka, N., Saito, Y. and Yoshida, S. Effects of Dextran Sulfate on Stabilization of Milk Lipoprotein Lipase and VLDL Triglyceride Hydrolysis in Vitro. Tohoku J. exp. Med., 1986, 149 (1), 61-66_The effects of dextran sulfate (DS), which has various molecular numbers, on hydrolysis of very low density lipoprotein triglyceride (VLDL-TG) by bovine milk lipoprotein lipase (LPL) and the stability of LPL were studied. VLDL-TG hydrolysis was increased by the addition of DS; DS caused linear increase in the Vmax for VLDL-TG with increase in its sulfate content, but did not change the $\mathrm{Km}$ value for VLDL-TG. DS also stabilized LPL, but this effect was not dependent on its sulfate content. These results suggest that the mechanism of action of DS in LPL stabilization may be different from that in enhancement of VLDL hydrolysis. lipoprotein lipase; dextran sulfate; very low density lipoproteins
\end{abstract}

Dextran sulfate (DS) is reported to cause liberation of lipoprotein lipase (LPL) from endotherial cells into the blood stream in vivo (Cohen and Tudhope 1956) and to increase hydrolysis of very low density lipoproteins (VLDL) by milk LPL (Matsuoka et al. 1982). DS consists of components of different molecular weight and different sulfate content (Yamada et al. 1961), and the components of different molecular weight are reported to have different effects on fibrinolysis (Yamada and Kuzuya 1962). The relationship between the molecular wight of DS and its effects on LPL is unknown. In the present study, we examined the relationship between the molecular weight of DS and its effects on stabilization of purified bovine milk LPL and on enhancement of hydrolysis of VLDLtriglyceride (TG) by LPL.

\section{Materials and Methods}

\section{Materials}

Heparin sodium salt (porcine intestinal mucosa, 169.9 USP units/mg), fatty acid-free bovine serum albumin (BSA), dextran and trioleoyl glycerol were purchased from Sigma.

Received December 9, 1985 ; accepted for publication April 16, 1986. 
TABLE 1. Various dextran sulfate and their sulfate content

\begin{tabular}{cccc}
\hline Dextran sulfate & M.W. & Sulfate content $(\%)$ & Inherent viscosity \\
\hline I & 1190 & 3.0 & 0.0272 \\
II & 1320 & 5.6 & 0.0414 \\
III & 1370 & 9.0 & 0.0379 \\
IV & 1920 & 15.9 & 0.0324 \\
\hline
\end{tabular}

Dextran sulfates were kindly provided by Kowa Co., Ltd. (Tokyo). The dextran sulfates used are shown in Table 1. Tri $\left[1^{1{ }^{14}} \mathrm{C}\right]$ oleoyl glycerol $(50 \mathrm{mCi} / \mathrm{mmole})$ was purchased from Japan Isotope Association. Lipoprotein lipase was purified from bovine skimmed milk by affinity chromatography on heparin-Sepharose (Iverius 1971) as described previously (Matsuoka et al. 1980).

Apolipoprotein C-II was a gift from Prof. Jackson (Cincinnati, OH, USA). It had been isolated from VLDL obtained from the plasma of fasting normal individuals (Jackson et al. 1977).

\section{Assay of lipoprotein lipase activity}

LPL was assayed by measuring release of $\left[1{ }^{14} \mathrm{C}\right]$-labeled fatty acids from tri $\left[1{ }^{-14} \mathrm{C}\right]$ oleoyl glycerol as described by Nilsson-Ehle et al. (1976). The standard assay mixture contained $0.378 \mu$ mole of trioleoyl glycerol, $2 \mathrm{nCi}$ of tri $\left[1-{ }^{14} \mathrm{C}\right]$ oleoyl glycerol emulsified with $0.02 \%$ Triton $\mathrm{X}-100,2 \%$ fatty acid free bovine serum albumin (BSA), $2.0 \mu \mathrm{g}$ of apolipoprotein $\mathrm{C}-\mathrm{II}$ and $50 \mathrm{mM}$ Tris- $\mathrm{HCl}, \mathrm{pH} 8.6$, in a final volume of $0.25 \mathrm{ml}$. Incubation was carried out for $30 \mathrm{~min}$ at $37^{\circ} \mathrm{C}$.

\section{Preparation of tri $\left[1{ }^{-14} \mathrm{C}\right]$ oleoyl glycerol labeled $V L D L$}

Very low density lipoproteins $(d<1.006)$ were isolated from normal human serum by ultracentrifugation. The once obtained VLDL by ultracentrifugation of human serum were dialysed againt a buffer containing $0.9 \% \mathrm{NaCl}, 10 \mathrm{mM}$ Tris- $\mathrm{HCl} \mathrm{pH} 7.4$ and were ultracentrifuged again at $105,000 \times \mathrm{g}$ for $22 \mathrm{hr}$, and the supernatant fractions were used for VLDL. Tri $\left[1{ }^{-14} \mathrm{C}\right]$ oleoyl glycerol was incorporated into normal human VLDL using dimethylsulfoxide, according to the method of Fielding (1979).

\section{$V L D L$-triglyceride ( $V L D L-T G$ ) hydrolysing activity}

The standard assay mixture contained $0.20 \mu$ mole of tri $\left[1-{ }^{14} \mathrm{C}\right]$ oleoyl glycerol labeled VLDL (S.A. $0.37 \mu \mathrm{Ci} / \mathrm{mole}, 6.26 \mathrm{mg} / \mathrm{ml}$ of triglyceride, $2.73 \mathrm{mg} / \mathrm{ml}$ of total cholesterol, 2.25 $\mathrm{mg} / \mathrm{ml}$ of phospholipid), $2 \% \mathrm{BSA}, 0.1 \mathrm{M}$ Tris- $\mathrm{HCl}(\mathrm{pH} 8.2)$ and $20 \mathrm{ng}$ of LPL, in a final volume of $0.25 \mathrm{ml}$. Incubation was carried out for $60 \mathrm{~min}$ at $37^{\circ} \mathrm{C}$. The $\left[1-^{14} \mathrm{C}\right]$-labeled fatty acids released from tri $\left[1-{ }^{14} \mathrm{C}\right]$ oleoyl glycerol-labeled VLDL were measured by the method of Nilsson-Ehle et al. (1976).

\section{Results And Discussion}

Tissues contain DS of various molecular numbers (Yamada et al. 1961), but relationship between different molecular numbers of DS and their physiological effects are not well known. We have previously reported that DS increases the hydrolysis of VLDL-TG by LPL (Matsuoka et al. 1982). In this series of experiments, we compared their effects on hydrolysis of VLDL by LPL with those on 

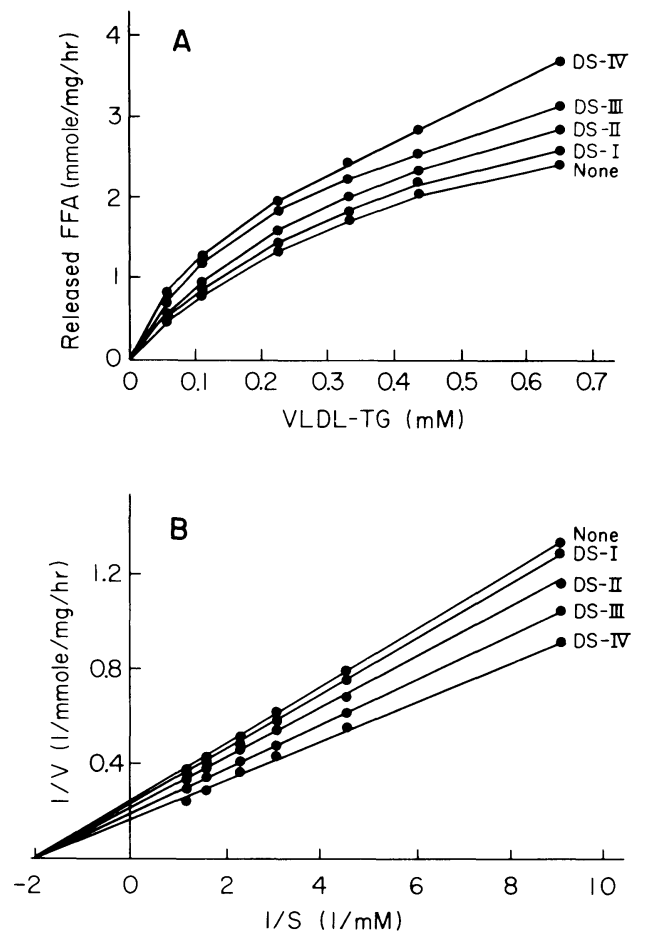

Fig. 1. A : Effects of DSs on hydrolysis of VLDL-TG at various concentrations of VLDL-TG. The incubation mixture consisted of the indicated concentration of tri $\left[11^{-14} \mathrm{C}\right]$ oleoyl glycerol-labeled VLDL, $2 \%$ BSA, $0.1 \mathrm{M}$ Tris-HCl, $\mathrm{pH} 8.2$, and $20 \mathrm{ng}$ of LPL, with or without DS $(10 \mathrm{ng} / \mathrm{ml})$ in a final volume of $0.25 \mathrm{ml}$. B : Lineweaver-Burk double reciprocal plots of VLDL-TG hydrolysis by LPL. Lineweaver-Burk plots $(1 / \mathrm{v}$ vs $1 / \mathrm{s})$ were constructed from the data in Fig. 1A.

stability of LPL. At first, the effects of various DSs on the hydrolysis of VLDL-TG were studied at various concentrations of VLDL-TG. Hydrolysis of VLDL-TG increased with an increase in the amount of individual DS added to incubation mixture as shown in Fig. 1A. To understand the mechanism of enchancement of hydrolysis of VLDL-TG, Lineweaver-Burk double reciprocal plots were made from Fig. $1 \mathrm{~A}$ and shown in Fig. 1B, and kinetic parameters were examined. The DS did not change the apparent $\mathrm{Km}$ value $(0.5 \mathrm{mM})$ for VLDLTG, but changed the Vmax value for VLDL-TG by LPL, which was largest with DS-IV (7.8 released FFA mmole/mg prot/hr). To understand the activation mechanism of LPL-catalyzed VLDL-TG hydrolysis by DS, the relationship between Vmax value for VLDL-TG hydrolysis and sulfate content of DS used in the experiments of Fig. 1B are shown in Fig. 2A. The Vmax value increased with an increase in the sulfate content of DS and the relationship between Vmax value and sulfate content of DS was linear. These results suggest that the sulfate 

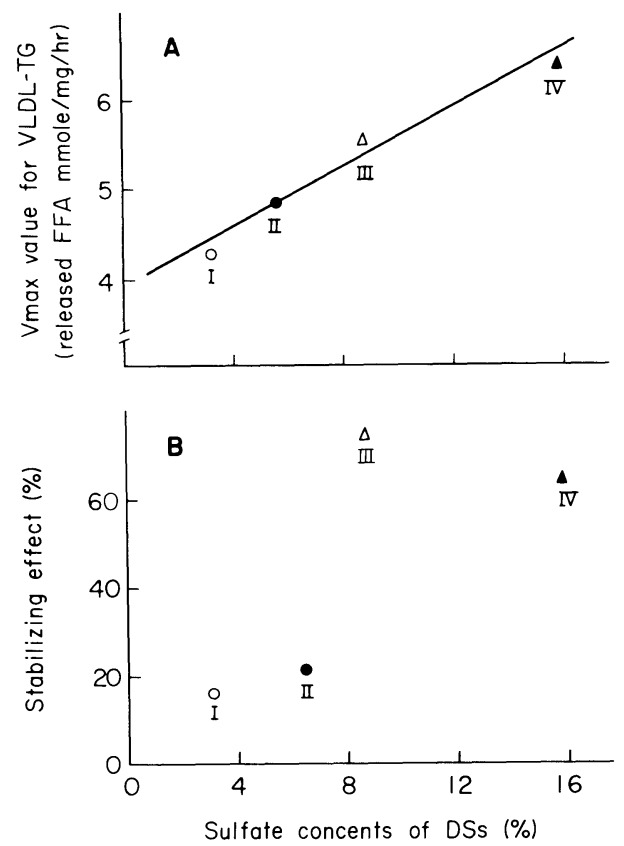

Fig. 2. A : Relationship between the change of Vmax value for VLDL-TG hydrolysis by various DSs and sulfate contents DSs. These values were constructed from Fig. 1B.

B : Relationship between the stabilizing effect of various DSs on LPL activity, and sulfate contents of DSs. The values were constructed from Table 1 at the preincubating condition at $37^{\circ} \mathrm{C}$ for $2 \mathrm{hr}$.

moiety of DS plays an important role in enhancing the effect of DS on the hydrolysis of VLDL by LPL.

In the next series of experiments, the effect of DS on the stability of LPL was examined. Enzyme activity was assayed after the LPL was preincubated at $37^{\circ} \mathrm{C}$ for indicated times. As shown in Table 2, LPL was inactivated by the incubation. In the treatment at $37^{\circ} \mathrm{C}$ for $1 \mathrm{hr}$ or $2 \mathrm{hr}$, DS-I and II did not stabilize the LPL activity, DS-III and IV prevented the loss of LPL activity to almost the same extent. At least, DS-IV was not better than DS-III. The relation of stabilizing effect of various DSs and sulfate content of DSs was shown in Fig. 2B. They were not in a linear relationship. These results indicated that the effects of DSs on LPL stabilization were not dependent on the sulfate content in contrast with the enhancing effects of DSs on VLDL-TG hydrolysis as shown in Fig. 2B. Clarke et al. (1983) recently reported that the types of complex produced by the combination of lipoprotein lipase with heparin were dependent on the molecular weight of heparin ( $\mathrm{Mr} 6600-18400$ ). Therefore, the stabilization of LPL by DSs may relate to the formation of complex with LPL and DS. The results obtained in the present experiments suggest that the mechanism of LPL stabilization by DS 
TABLE 2. Effects of DSs on LPL stability

\begin{tabular}{lcccrccc}
\hline & \multicolumn{9}{c}{$37^{\circ} \mathrm{C}$} \\
\cline { 2 - 7 } Pextran sulfate & \multicolumn{3}{c}{$1 \mathrm{hr}$} \\
\hline None & 35.9 & \pm & 7.9 & 11.7 & \pm & 5.2 \\
I & 29.5 & \pm & 1.3 & & 13.4 & \pm & 4.4 \\
II & 20.9 & \pm & 4.0 & 6.2 & \pm & 2.5 \\
III & 70.3 & \pm & 9.4 & 68.6 & \pm & 5.3 \\
IV & 69.6 & \pm & 6.6 & & 53.2 & \pm & 7.4 \\
\hline
\end{tabular}

Mixtures of $0.4 \mu \mathrm{g}$ of LPL, $1 \mathrm{mg}$ of BSA with or without various DSs $(0.2 \mu \mathrm{g} / \mathrm{ml})$ and $0.1 \mathrm{M}$ Tris- $\mathrm{HCl}, \mathrm{pH} 8.2$, were preincubated at $37^{\circ} \mathrm{C}$ for indicated times. After preincubation $0.05 \mathrm{ml}$ of the mixtures were added to LPL activity assay mixture in order to measure the enzyme activity. These assay mixtures contained $0.378 \mu$ mole of tri $\left[1-^{14} \mathrm{C}\right]$ oleoyl glycerol emulsified with $0.02 \%$ Tritox X-100, $2 \%$ BSA, $2.0 \mu \mathrm{g}$ of apolipoprotein $\mathrm{C}-\mathrm{II}$ and $50 \mathrm{mM}$ Tris $\mathrm{HCl}, \mathrm{pH} 8.6$ in a final volume of $0.25 \mathrm{ml}$. Values represent the percentage of initial activity.

is different from that of its effect on an increase in VLDL-TG, hydrolysis. But, DS-III and IV had a greater stabilizing effect than DS-I and II. Therefore, the stabilizing effect of DS may be partly involved in the enhancing effect of DS on VLDL-TG hydrolysis. Experiments are now in progress to clarify the mechanism of action of DS on the action of LPL.

\section{References}

1) Clarke, A.R., Luscombe, M. \& Holbrook, J.J. (1983) The effect of the chain length of heparin on its interaction with lipoprotein lipase. Biochim. biophys. Acta, 747, 130137.

2) Cohen, H. \& Tudhope, G.R. (1956) Dextran sulfate: Use as an anticoagulant, and action in lowering serum cholesterol. Brit. med. J., 2, 1023-1027.

3) Fielding, C.J. (1979) Validation of a procedure for exogenous isotopic labeling of lipoprotein triglyceride with radioactive triolein. Biochim. biophys. Acta, 573, 255265.

4) Iverius, P.H. (1971) Coupling of glycosaminoglycans to agarose beads (Sepharose 4B). Biochem. J., 124, 677-683.

5) Jackson, R.L., Baker, H.N., Gilliam, E.B. \& Gotto, A.M. (1977) Primary structure of very low density apolipoprotein C-II of human plasma. Proc. nat. Acad. Sci. USA, 74, 1942-1945.

6) Matsuoka, N., Shirai, K. \& Jackson, R.L. (1980) Preparation and properties of immobilized lipoprotein lipase. Biochim. biophys. Acta, 620, 308-316.

7) Matsuoka, N., Shirai, K., Saito, Y. \& Kumagai, A. (1982) Effect of dextran sulfate on the interaction between very low density lipoprotein and lipoprotein lipase. Biochim. biophys. Acta, 712, 221-224.

8) Nilsson-Ehle, P., Garfinkel, A.S. \& Schotz, M.C. (1976) Rapid determination of lipoprotein lipase activity in human adipose tissue. Biochim. biophys. Acta, 431, $147-156$.

9) Yamada, K. \& Kuzuya, H. (1962) Clinical application of heparin and heparinoids. 
Saishinigaku, 17, 2605-2617. (Japanese)

10) Yamada, K., Kuzuya, H. \& Noda, M. (1961) Studies on some actions of sulfated polisaccharides on actherosclerosis. I. Toxicity, lipolytic action and anti coagulant activity. Jap. Circulat. J., 25, 497-502. 